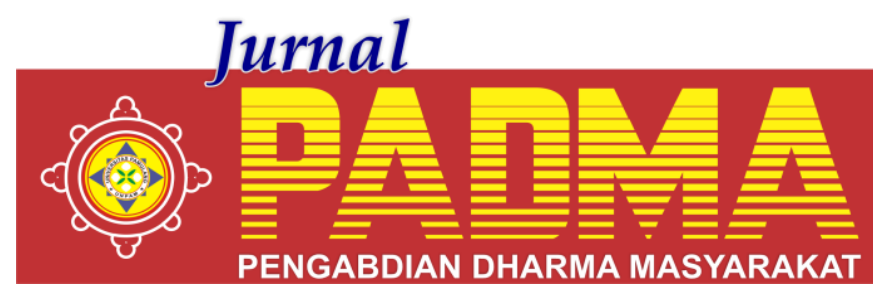

VOLUME 1, NOMOR 2, APRIL 2021

\title{
PENINGKATAN MINAT WIRAUSAHA PADA SISWA SMK MUHAMMADIYAH PARUNG KABUPATEN BOGOR
}

\author{
${ }^{1 *}$ Irfan Rizka Akbar, ${ }^{2}$ Denok Sunarsi, ${ }^{3}$ Muhamad Musyfiq Salami, ${ }^{4}$ Sarwani, ${ }^{5}$ Mukhlis Catio \\ Universitas Pamulang, Tangerang Selatan, Banten Indonesia \\ *dosen02461@unpam.ac.id
}

\begin{abstract}
Abstrak
Penyuluhan wirausaha home industry untuk meningkatkan semangat wirausaha, hadir untuk memberikan pengetahuan, wawasan dan peluang yang sangat potensial dikembangkan, karena bahan bakunya murah dan mudah diperoleh. Tujuan dari penyuluhan wirausaha home industry untuk semangat wirausaha agar siswa siswi SMK Muhammadiyah Parung dapat meningkatkan berkreasi, berkarya dan berdaya juang untuk mengubah barang bekas yang tidak bernilai secara ekonomis menjadi barang yang bernilai guna serta bernilai ekonomi tinggi.
\end{abstract}

Kata Kunci : Wirausaha

\begin{abstract}
Home industry entrepreneurship counseling to increase the entrepreneurial spirit is here to provide knowledge, insights and opportunities that have the potential to be developed, because the raw materials are cheap and easy to obtain. The aim of the home industry entrepreneurship counseling is for the spirit of entrepreneurship so that students of Muhammadiyah Parung Vocational School can increase their creativity, work and struggle to convert used goods that are not economically valuable into goods that are of useful and
\end{abstract} high economic value.

Keywords: Entrepreneur.

\section{PENDAHULUAN}

Belajar sudah rnenjadi salah satu hal yang sangat penting, terutarna untuk anak remaja. Ini masalahnya, rernaja sekarang cenderung rnalas belajar dan rnernilih untuk rnelakukan kegiatan lain yang rnereka anggap lebih rnenarik. Rernaja yang rnalas belajar tentu rnerniliki alasan berbeda, ada yang rnerasa bosan dengan pelajaran karena nilainya terus rnenurun, ada yang tidak rnerniliki antusiasrne untuk belajar dan ada yang sulit berkonsentrasi ketika disuruh belajar, ada yang tidak rnerniliki sernangat untuk belajar, dan ada pula yang susah untuk berkonsentrasi ketika disuruh belajar, ada hal lain dalam dunia SMK yaitu wirausaha.

Usia rernaja rnernang rentan terhadap hal-hal baru seperti lingkungan dan pergaulan baru, hal ini juga rnenjadi salah satu faktor rnengapa rernaja banyak yang rnalas untuk berwirausaha karena juga dimanja oleh orang tua masing masing. Oleh karena itu, Pengabdian kepada Masayarakat ini menjadi solusi penyuluhan yang positif untuk mengarahkan kembali untuk giat berwirausaha dan mandiri dalam menghasilkan. Manfaat Pengabdian Keapda Masyarakat

Mewujudkan salah satu Tri Dharma Perguruan Tinggi yaitu Pengabdian kepada masyarakat sehingga mampu mencan permasalahan dalam masyarakat Memperdalam wawasan dan pengetahuan dosen dan mahasiswa, tentang permasalahan di dalam lingkungan masyarakat. Melatih mahasiswa menelaah dan memecahkan setiap masalah yang ada didalam masyarakat. Memberikan pengalaman dan melatih mahasiswa dalam melaksanakan kegiatan pengabdian kepada masyarakat Memperluas jaringan, melatih menggunakan ilmu yang didapatkan dibangku perkuliahan,

\section{METODE}

Dengan menggunakan diskusi kelompok, penyuluhan ini mengedukasi SMK Muhammadiyah Parung akan pemanfaatan limbah plastic (bungkus kopi instan) Akhir- 
akhir ini berita mengenai limbah plastik semakin mengkhawatirkan. Pasalnya limbah plastik ini bukan hanya ada di daratan saja, melainkan di lautan. Namun tak semua yang berbahan plastik harus berakhir menjadi limbah. Pasalnya ada pula yang menggunakan plastik sebagai bahan kerajinan dan juga meningkatkan kreativitas. Salah satu yang sering digunakan ialah bungkus kopi. Bungkus kopi sendiri cukup sering dikreasikan menjadi berbagai hal seperti dompet maupun tas, terutama oleh para siswa menjadi lahan wirausaha.

Cara membuat tas dari bungkus kopi ini termasuk ramah lingkungan. Karena bisa membantu untuk mengurangi sampah plastik. Selain itu, tentu saja hasil dari kerajinan ini bisa kamu gunakan dan juga ramah lingkungan. Untuk cara membuat tas dari bungkus kopi ini pun membutuhkan tingkat kreativitas serta keahlian. Tapi bila kamu belum bisa dan mengetahui cara membuat tas dari bungkus kopi, kamu bisa berlatih secara mandiri ataupun dengan bantuan orang lain. Karena sampah plastik sendiri termasuk dalam jenis sampah yang susah terurai, maka mendaur ulang dengan cara membuat tas dari bungkus plastik ini patut untuk kamu coba. Bahkan tas daur ulang ini bisa digunakan untuk menaruh barang saat berbelanja.

\section{HASIL DAN PEMBAHASAN}

Kegiatan Pengabdian Kepada Masyarakat ini berkaitan erat dengan menumbuhkan wirausaha siswa. Pemahaman akan pentingnya melatih diri untuk berwirausaha haruslah disadari oleh usia remaja, dan sekolah menengah harus bisa membimbing setiap pelajar untuk dapat memahami bisnis dengan baik. Meskipun sebenarnya sekolah lebih utama, akan tetapi pemahaman tentang memulai bisnis perlu diberikan, untuk kemandirian individu. Fokus utama dalam aktivitas menumbuhkan semangat pengusaha muda ini memang harusnya disebar secara tersirat dalam mata pelajaran ekonomi dan akuntansi. Hal itu haruslah didasarkan pada intensitas perencanaan, kesiapan berpartisipasi dalam kehidupan sebagai pribadi yang independent, dan keterarahan individuindividu kepada tujuan. Didukung minat mereka untuk berbisnis yang sangat kuat.
Masalah pengelolaan binis siswa di SMK lebih mengacu pada hal-hal berikut:

Perilaku yang konsumtif sering tak disadari. Alhasil, banyak orang yang begitu konsumtif sehingga perlahan binisnya menjadi bermasalah. Uang yang diterima mungkin tinggi namun tidak ada yang bisa ditabung di akhir bulan. Bila Siswa pernah terpikir kenapa belum ada dana yang ditabung padahal Siswa sudah memiliki uang saku yang melebihi jumlah pengeluaran yang seharusnya, mungkin perilaku konsumtif Siswa yang menjadi penyebabnya. Remaja yang konsumtif biasanya membeli barang yang sebenarnya tidak terlalu ia butuhkan, membelanjakan uang untuk keperluankeperluan yang tidak penting, gaya hidup yang terlalu hura-hura, dan sebagainya. Untuk itui dibuatlah solusi, tahan selera Siswa. Siswa harus mementingkan kebutuhan; mana yang harus dipenuhi dan mana yang sebenarnya kurang penting, dalam artian, terpenuhi atau tidaknya hal tersebut tidak akan mempengaruhi Siswa.

Bila Siswa sudah memiliki suatu barang, usahakan agar tidak membeli barang dengan fungsi yang sama namun harganya lebih mahal. Buat apa punya dua barang dengan fungsi yang sama? Meski mungkin, yang lebih mahal tentu lebih bagus dan lengkap fungsinya. Siswa juga harus tahu tujuan Siswa dalam mengalokasikan dana. Bila Siswa tidak bijak dalam menetapkan tujuan pembelanjaan, Siswa hanya akan membelanjakan uang Siswa untuk berbagai keperluan yang sebenarnya tidak perlu.

Tak bisa dipungkiri, anak muda memang senang menghabiskan waktu untuk berkumpul/nongkrong, menikmati sesuatu yang sedang tren, berusaha untuk terus sejalan dengan perkembangan terkini dalam berbagai bidang, dan sebagainya. Apalagi bagi siswa yang belum memiliki tanggungan atau masih lajang. Karena belum memiliki tanggungan, ia merasa belum bertanggung jawab untuk Semangat pengusaha mudanya karena pendapatannya hanya untuknya. Jadi, anggapan bahwa penghasilannya hanya untuknya seakan melekat dalam dirinya.

Oleh karena itu, siswa kerap menghabiskan uang untuk memanjakan dirinya tanpa disadari. Perlahan binisnya pun menjadi tak terkontrol. Setiap bulan uang habis tanpa sisa untuk ditabung, 
menunggu bulan depan untuk gajian kembali. Bila pun ada sejumlah dana yang tersisa, Siswa umumnya menggunakan uang tersebut untuk bersenang-senang, bukan menabung atau berinvestasi.

Solusi sepenuhnya ada di dalam diri Siswa. Harus mencoba untuk menemukan pola yang tepat ketika membelanjakan uang. Bila Siswa merasa bahwa selama ini sudah terlalu banyak menghamburkan uang untuk bersenang-senang, mungkin Siswa benar. Meskipun sekarang ini Siswa belum memiliki tanggungan, siswa harus mencoba untuk berhemat, mengatur pengeluaran dengan membandingkan mana yang prioritas dan mana yang tidak begitu mendesak.

Semangat kewirausahaan harus bisa dihadirkan dengan baik dan terstuktur sehingga siswa lebih senang terhadap wirausaha di bandingkan dengan konsumsi uang tersebut.

Solusinya dari sekarang Siswa harus bisa menyisihkan sejumlah uang yang kemudian dialokasikan khusus untuk belajar bermodal untuk wirausaha dan mendapatkan pembelajaran langsung terhadap apa yang di hadapi yaitu konsumen dan pengeloaan keuangan atas apa yang di usahakan.

\section{PENUTUP}

Acara kegiatan pengabdian kepada masyarakat ini dilaksanakan selama 3 hari, yaitu sebagai berikut.Pertama, pembukaan oleh Kepala SMK Muhammadiyah Parung kemudian dilanjutkan laporan dari Ketua Kegiatan sekaligus penjelasan pelatihan dan pembagian bahan praktek dan contoh model produk .Selanjutnya yaitu pemberian motivasi berwirausaha oleh narasumber. Kedua, kegiatan demonstrasi pembuatan produk usaha berbahan dasar sampah plastik. Ketiga yaitu kegiatan penyuluhan mengenai bagaimana hasil produk tersebut dibuat sebagai kegiatan wirausaha.

\section{DAFTAR PUSTAKA}

Achmad, Nur dan Saputro, Edy Purwo. 2015. Isu Riset Kewirausahaan. Jakarta: Direktorat Penelitian Pengabdian Masyarakat Dirjen Dikti.

Achmad, Nur. 2015. Kewirausahaan: Suatu Alternatif Lain Menuju Kesuksesan. Surakarta: BPK FEB UMS.
Achmad, Nur., Saputro, Edy Purwo dan Handayani, Sih. 2016. Kewirausahaan di Era Digital. Jakarta: Direktorat Penelitian Pengabdian Masyarakat Dirjen Dikti.

Ajimat, A., Sunarsi, D., \& Sidiq, F. (2020). Berwirausaha Memanfaatkan Media Sosial Pada Daerah Sepatan. ADI Pengabdian Kepada Masyarakat, 1(1), 69-76.

Akintoye, A. S dan MacLeod, M. J. 1996.Risk Analysis and Management in Contruction. International Journal of Project Management. Vol. 15, No. 1, pp. 31-38.

Drucker. Peter. F. 1993. Inovasi Dan Kewiraswastaan. Jakarta:

Effendy, A., \& Sunarsi, D. (2020). Persepsi Mahasiswa Terhadap Kemampuan Dalam Mendirikan UMKM Dan Efektivitas Promosi Melalui Online Di Kota Tangerang Selatan. Jurnal Ilmiah MEA (Manajemen, Ekonomi, \& Akuntansi), $\quad 4(3), \quad$ 702-714. https://doi.org/10.31955/mea.vol4.iss 3.pp702-714

Erlangga. Effendy, Mochtar. 2010. Kewirausahaan (Entrepreneurship) Tuntunan Untuk Praktisi. Yayasan Penerbit Al-Mukhtar : Palembang.

Handoko T. Hani. 2003. ManajemenEdisi 2. Yogyakarta : BPFE-Yogyakarta

Haque, M. G., et al (2021). Competitive Advantage in Cost Leadership and Differentiation of SMEs "Bakoel Zee" Marketing Strategy in BSD. PINISI Discretion Review, 4(2), 277-284.

Sunarsi, D., Kustini, E., Lutfi, A. M., Fauzi, R. D., \& Noryani, N. (2019). Penyuluhan Wirausaha Home Industry Untuk Meningkatkan Ekonomi Keluarga Dengan Daur Ulang Barang Bekas. BAKTIMAS: Jurnal Pengabdian pada Masyarakat, 1(4), 188-193. 